\title{
Softer, Higher-Friction Flooring Improves Gait of Cows With and Without Sole Ulcers
}

\author{
F. C. Flower, ${ }^{\star 1}$ A. M. de Passillé,† D. M. Weary, ${ }^{\star}$ D. J. Sanderson, $\ddagger$ and J. Rushen† \\ *Animal Welfare Program, Faculty of Food and Land Systems, The University of British Columbia, Vancouver, Canada V6T 1 Z4 \\ †Agriculture and Agri-Food Canada, Agassiz, British Columbia, Canada VOM 1A0 \\ $\ddagger$ School of Human Kinetics, The University of British Columbia, Vancouver, Canada V6T 1Z1
}

\section{ABSTRACT}

We studied dairy cows $(\mathrm{n}=30)$ walking on concrete and on a soft, high-friction composite rubber surface to examine how flooring influenced gait and how this differed for cows with hoof lesions. Cows had hooves trimmed 9 wk after the trial and were classified as either with or without sole ulcers. Video recordings of the cows while walking were digitized using motion analysis software to calculate stride variables (length, height, overlap, duration, proportion of triple support, and speed). Gait was scored by a subjective scoring system ( 1 = sound to $5=$ severely lame $)$ and by a continuous visual analog scale for each of 7 gait attributes. Cows with sole ulcers walking on a composite rubber surface had longer strides (156.9 \pm 2.6 vs. $149.6 \pm 2.6$ $\mathrm{cm})$, higher stride heights $(9.7 \pm 0.3$ vs. $8.8 \pm 0.3 \mathrm{~cm})$, more stride overlap $(0.4 \pm 2.0 \mathrm{vs} .-4.3 \pm 2.0 \mathrm{~cm})$, shorter periods of triple support (3 legs in ground contact; 68.6 \pm 2.0 vs. $73.8 \pm 2.0 \%)$, walked faster $(1.22 \pm 0.04$ vs. $1.17 \pm 0.04 \mathrm{~m} / \mathrm{s})$ and had lower overall gait scores $(2.9$ \pm 0.1 vs. $3.1 \pm 0.1$ ), better tracking-up (19 \pm 2 vs. $24 \pm$ 2 ), better joint flexion ( $29 \pm 2 \mathrm{vs} .33 \pm 2$ ), more symmetric steps ( $31 \pm 3$ vs. $36 \pm 3$ ), and less reluctance to bear weight on their legs (12 \pm 2 vs. $16 \pm 2)$ compared with walking on concrete. Similar results were found for cows without sole ulcers. Most of the subjective gait measures could distinguish between cows with and without sole ulcers, but this was not the case for kinematic measures other than stride height. Cows with higher gait scores (more severe lameness) showed the greatest improvement in stride length $(\mathrm{r}=-0.51)$, triple support $(\mathrm{r}=0.59)$, swing duration $(\mathrm{r}=-0.44)$, overall gait score $(\mathrm{r}=0.46)$, and reluctance to bear weight $(\mathrm{r}=$ 0.66) when walking on the rubber surface compared with cows with lower gait scores. These results indicate that rubber flooring provides a more secure footing and

Received June 23, 2006.

Accepted November 13, 2006.

${ }^{1}$ Corresponding author: frances.flower@animalcompassion foundation.org is more comfortable to walk on, especially for lame cattle.

Key words: dairy cattle, lameness, sole ulcer, flooring

\section{INTRODUCTION}

Concrete flooring is widely used in dairy barns because of its low cost, durability, and ease of cleaning; however, concrete surfaces are a risk factor for lameness and the development of hoof pathologies such as sole and white line hemorrhages, sole ulcers (SU), digital dermatitis, and heel erosion (Wells et al., 1999; Vokey et al., 2001; Somers et al., 2005). Hoof injuries and disease are a concern for dairy producers because of the large numbers of cows affected (Clarkson et al., 1996; Cook, 2003; Whitaker et al., 2004), and because such injuries can cause pain, reduce feed intake (O'Callaghan, 2002) and milk production (Green et al., 2002), and increase reproductive problems (Hernandez et al., 2005).

Recent research has shown that flooring that is softer or has higher surface friction can improve some measures of cow mobility. For example, cows had longer strides and more joint angulation on high- vs. low-friction concrete (Phillips and Morris, 2001), and cows walked faster and slipped less on soft, high-friction rubber vs. lower-friction concrete floors (Rushen and de Passillé, 2006).

Little research has investigated the effects on gait of cows with hoof injuries and disease on softer, more yielding flooring. Telezhenko and Bergsten (2005) reported that rubber mats improved gait (e.g., increased stride length) for both lame and nonlame cows compared with solid concrete. However, because of barn design constraints, cows were exposed to the same order of flooring surface, potentially confounding flooring effects. Although alternatives to concrete flooring would appear beneficial for lame cows, this has not been tested systematically. Understanding these effects will provide a basis for recommending more suitable flooring, particularly for lame cows.

Kinematic gait analysis and subjective gait scoring were used to characterize the gait of cows and distin- 
guish cows with SU from healthy ones (Flower et al., 2005; Flower and Weary, 2006). The aim of the current study was to use both techniques to compare cow gait on concrete flooring and a composite rubber surface, and to determine how these changes are affected by lameness and hoof pathologies.

\section{MATERIALS AND METHODS}

\section{Cows and Management}

Thirty Holstein dairy cows (parity 1 to 8; BW $641 \pm$ $75 \mathrm{~kg}$, mean $\pm \mathrm{SD}$ ), of which 28 were lactating (DIM $164 \pm 68 \mathrm{~d}$, milk production $26.8 \pm 6.1 \mathrm{~kg} / \mathrm{d}$ ), were used from the herd at the Dairy and Swine Research and Development Centre, Agriculture and Agri-Food Canada, Lennoxville, Quebec, Canada. Cows were selected from the available animals in the herd that were not being used in other experiments. All cows were housed in tie stalls on rubber-filled geotextile mattresses with a covering of chopped straw. Cows were milked in the parlor at 0700 and $1900 \mathrm{~h}$ daily, fed a TMR formulated to meet or exceed NRC (2001) requirements supplied ad libitum, and had free access to water in self-filling troughs. Cows were cared for according to the standards of the Canadian Council on Animal Care, and the experimental protocol was approved by the Institutional Animal Care Committee of the Lennoxville Research Centre.

\section{Data Collection}

Video Recordings. Cows were filmed walking along 1 of 2 identical $1.1 \times 22.4 \mathrm{~m}$ corridors (Rushen and de Passillé, 2006). A rope barrier between the 2 corridors forced cows to walk in a straight line with minimal side-to-side movement. During a habituation phase, the cows were trained to walk through each corridor over $2 \mathrm{~d}$, and at the end of each corridor a food reward (a mixture of grain and hay) was offered.

The floor of each corridor was covered with 1 of 2 flooring surfaces: ungrooved concrete or a composite rubber surface composed of a bottom Animat layer (1.9 cm thick; Animat Inc., Saint-Élie d'Orford, QC, Canada), a middle layer of felt ( $1.5 \mathrm{~cm}$ thick, polypropylene/ polyester mix), and a top surface of high-friction slipresistant rubber (0.6 cm thick, \#125 2-ply; Cobelt Canada Inc., Saint-Laurent, QC, Canada). The total thickness of the composite rubber surface was $4.0 \mathrm{~cm}$. The types of material are described in more detail by Rushen and de Passillé (2006), who reported that static and dynamic coefficients of friction and degrees of compressibility were substantially higher on the composite rubber surface than on concrete.
We examined the gait of cows walking on both surfaces in both corridors using a balanced design within cow. Cows were randomly allocated to 2 groups and each group was tested over $2 \mathrm{~d}$. Group $1(\mathrm{n}=16)$ was filmed on the first day with the composite rubber surface in corridor 1 and concrete in corridor 2 , and on the second day the surfaces were switched. Group $2(n=14)$ was filmed on the first day with the composite rubber surface in corridor 2 and concrete in corridor 1, and on the second day the surfaces were switched. Each cow was tested alternately on each surface, with the order of exposure to the flooring surfaces balanced across cows. All testing was performed between 0900 and 1400 h. Corridors were cleaned manually at the beginning of each test to minimize the occurrence of slipping.

Two video cameras were fixed in position $9.6 \mathrm{~m}$ from the corridors and perpendicular to the direction of movement of the cows. One camera was used for kinematic analysis (Panasonic AG-456UP; Matsushita Electric, Mississauga, ON, Canada) and the other was used for gait scoring (Sony Video8 Handycam Camcorder CCD-FX730V; Sony Corporation, Park Ridge, NJ). Both cameras filmed the cows from the right side while they were walking in the midsection of the alley (length 7.4 m). Cameras (Panasonic WP-310; Matsushita Electric) were positioned above the corridors to obtain a posterior view of cows as they walked. At every recording session, at least 2 consecutive strides were recorded per cow. To supply adequate light, a $500-\mathrm{W}$ helium floodlight was attached above the kinematic analysis and gait scoring cameras and was directed at the corridors. Three 100-W light bulbs were placed in the ceiling above the alley as an additional lighting source.

On both test days, cows were walked (for a food reward) at least 3 times per corridor per day, although only the last 2 passages of each corridor per day were assessed. Thus, for each cow, 4 passages on each surface were scored over the test days. Of the 240 passages scored, 10 were not used because cows tripped, slipped, stopped, jumped, trotted, or ran.

Kinematic Gait Analysis. Cows were fitted with reflective markers, which were wrapped around the entire circumference of each leg directly above the metacarpo- and metatarsophalangeal joints at least $1 \mathrm{~h}$ before filming (Flower et al., 2005). Each marker was visible from all angles. The video recordings were digitized using PEAK Motus 7.1.1 (Peak Performance Technologies, Inc., Englewood, CO), and hoof strike and toeoff events were defined visually from the video recordings by 1 observer. Hoof strike occurred when the hoof first contacted the ground at the beginning of the stance phase. Toe-off occurred when the toe left the ground at the end of the stance phase. Basic kinematic measures (stride length, maximum stride height, stride 
Table 1. Description of the kinematic stride variables

\begin{tabular}{|c|c|}
\hline Variable & Description \\
\hline Stride length, $\mathrm{cm}$ & Horizontal displacement between 2 consecutive hoof strikes of the same hoof. \\
\hline Maximum stride height, $\mathrm{cm}$ & Maximum vertical displacement between 2 consecutive hoof strikes of the same hoof. \\
\hline \multicolumn{2}{|r|}{ 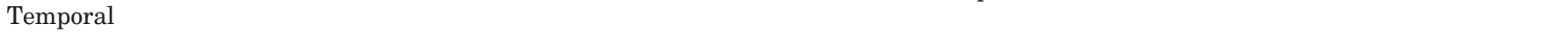 } \\
\hline Swing duration, $\mathrm{s}$ & Time the hoof is not in contact with the ground (interval between toe-off and following hoof strike). \\
\hline Speed, $\mathrm{m} / \mathrm{s}$ & Stride length/stride duration. \\
\hline Triple support, \% & (Sum of intervals between toe-off and subsequent contralateral hoof strike/stride duration) $\times 100$. \\
\hline
\end{tabular}

duration, stance and swing durations, and hoof speed) as well as triple support and stride overlap were then calculated according to the criteria given in Table 1 . Measures were averaged across the 4 hooves to provide 1 value per cow for each surface.

Subjective Gait Assessment. An experienced observer scored each cow's gait, using the video recordings from both posterior and lateral views, based on a numerical rating system (NRS) from 1 to 5 , where $1=$ sound and $5=$ severely lame (Flower and Weary, 2006). Previous scoring systems have classified cows with scores of 3 and higher as lame (Manson and Leaver, 1988; Whay et al., 1997); however, we treated lameness as a continuum. In addition, 6 specific gait attributes (back arch, head bob, tracking-up, joint flexion, asymmetric gait, and reluctance to bear weight) were scored using 100-unit continuous visual analog scales (Flower and Weary, 2006). A seventh behavior was scored using a visual analog scale: Abduction/adduction was assessed from a posterior view and was defined as swinging the hind limbs either away from (abduction) or toward (adduction) the body in a circular motion during the swing phase of the stride. The ends of the visual analog scale had a description of the extreme forms of the condition. For example, degree of back arch was defined as "flat" at one end (0) of the scale and "convex" at the other end (100), where "convex" represented the most extreme back arch the observer had seen in his or her experience. The observer recorded directly on a computer screen a position on the scale that represented the severity of the attribute. Each video recording was observed 9 times: twice for NRS, once for back arch and head bob, once for tracking-up, once for joint flexion, once for asymmetric gait, once for reluctance to bear weight, and twice for abduction/adduction. The observer assessed the gaits of all cows for 1 passage before scoring the next passage. A subsample of 13 cows was rescored by the same observer at the end of the study to test intraobserver consistency.
Clinical Assessment of Hooves. All cows were clinically examined for hoof pathologies on the day following gait assessment and again 9 wk later, because sole hemorrhages become visible only 8 to $10 \mathrm{wk}$ after corium damage occurs (Bergsten and Frank, 1996; Lischer and Ossent, 2000). During the first assessment, a trained observer examined cows for the presence of digital dermatitis, interdigital hyperplasia, interdigital necrobacillosis, and mature or healed SU. During the second assessment, a professional hoof trimmer trimmed and examined the front and hind hooves of cows and recorded the presence of sole and white line hemorrhages, SU, and heel erosion using the hoof health scoring system of Neveux et al. (2006). Cows with hoof pathologies were treated at the end of the trial.

At the time of the first clinical hoof assessment, 1 cow had an SU and this cow was also recorded as having an SU at the second hoof assessment. No other cows had visible hoof pathologies at the first assessment. Of the 30 cows examined during the second hoof assessment, the majority $(76 \%)$ had 1 or more hoof pathologies. Cows were grouped into 3 mutually exclusive categories based on hoof health: healthy cows with no visible signs of injury or disease on hooves $(n=7)$; cows having only sole and white line hemorrhages $(\mathrm{n}=13)$; and cows with SU ( $n=10)$. Hoof inspections revealed that cows with SU also had sole and white line hemorrhages.

Morphometric Measures. The mean BW of each cow was recorded once, and height at the third thoracic vertebrae (withers), height at the first coccygeal vertebrae (tailbone), and the length of the back (point of the withers-point of the tailbone) were measured 3 times from the left side. Measurements were taken when cows were standing with the head raised and legs straight. Mean BW ( \pm SD) was $641 \pm 75 \mathrm{~kg}$, height at the withers was $143 \pm 3 \mathrm{~cm}$, height at the tailbone was $146 \pm 3 \mathrm{~cm}$, and length of the back was $126 \pm 6 \mathrm{~cm}$. There were no differences in body size between the hoof health groups. 
Table 2. Least squares means \pm SEM of basic kinematic stride variables on concrete and a composite rubber surface, for cows with no sole ulcers (nSU; $n=20)$ and cows with sole ulcers (SU; $n=10$ )

\begin{tabular}{|c|c|c|c|c|c|c|c|}
\hline \multirow[b]{2}{*}{ Variable } & \multicolumn{2}{|c|}{$\mathrm{nSU}$} & \multicolumn{2}{|c|}{ SU } & \multicolumn{3}{|c|}{$P^{1}$} \\
\hline & Concrete & Rubber & Concrete & Rubber & $\mathrm{S}$ & $\mathrm{H}$ & $\mathrm{S} \times \mathrm{H}$ \\
\hline tric & $152.2 \pm 1.8$ & $156.9 \pm 1.8$ & $149.6 \pm 2.6$ & $156.9 \pm 2.6$ & 0.001 & $>0.10$ & $>0.10$ \\
\hline Stride & $9.6 \pm 0.2$ & $10.6 \pm 0.2$ & $8.8 \pm 0.3$ & $9.7 \pm 0.3$ & 0.001 & 0.019 & $>0.10$ \\
\hline Stri & $0.9 \pm 1.4$ & $3.7 \pm 1.4$ & $-4.3 \pm 2.0$ & $0.4 \pm 2.0$ & 0.001 & 0.089 & 0.058 \\
\hline Stri & $1.28 \pm 0.02$ & $1.27 \pm 0.02$ & $1.29 \pm 0.03$ & $1.31 \pm 0.03$ & $>0.10$ & $>0.10$ & $>0.10$ \\
\hline Stance duration, s & $0.86 \pm 0.02$ & $0.85 \pm 0.02$ & $0.88 \pm 0.03$ & $0.88 \pm 0.03$ & $>0.10$ & $>0.10$ & $>0.10$ \\
\hline Swing duration, s & $0.42 \pm 0.01$ & $0.42 \pm 0.01$ & $0.41 \pm 0.01$ & $0.43 \pm 0.01$ & 0.028 & $>0.10$ & 0.037 \\
\hline Speed, $\mathrm{m} / \mathrm{s}$ & $1.21 \pm 0.03$ & $1.26 \pm 0.03$ & $1.17 \pm 0.04$ & $1.22 \pm 0.04$ & 0.004 & $>0.10$ & $>0.10$ \\
\hline Triple support, \% & $69.7 \pm 1.4$ & $66.9 \pm 1.4$ & $73.8 \pm 2.0$ & $68.6 \pm 2.0$ & 0.001 & $>0.10$ & $>0.10$ \\
\hline
\end{tabular}

${ }^{1} P$-values for the effects of surface (S: concrete vs. rubber), hoof health (H: nSU vs. SU), and their interaction $(\mathrm{S} \times \mathrm{H})$

\section{Statistical Analyses}

Mean values were calculated for the kinematic stride variables using the first stride on the video recording per passage and averaging across the 4 hooves and 2 $\mathrm{d}$ of video recordings to provide 1 value per cow for each surface. Subjective gait assessment variables were averaged to provide 1 value per cow per surface. Pearson correlation coefficients were calculated between first and second observations of a subsample of cows $(\mathrm{n}=13$; SAS Institute, 1985) to test intraobserver reliability of the subjective gait variables.

Previously, Flower et al. (2005) and Flower and Weary (2006) found no differences in gait measures between cows with sole hemorrhages and healthy animals; therefore, we initially compared cows with sole and white line hemorrhages vs. healthy cows (1 df) using a GLM (SAS Institute, 1985). There were no differences for any variables (mean NRS \pm SEM for healthy cows was $2.5 \pm 0.1$ and was $2.4 \pm 0.1$ for cows with hemorrhages; $P>0.10$ ), so these cows were grouped together as animals with no SU (nSU; $\mathrm{n}=$ 20). Variables were then tested using a Mixed model, specifying cow as a random effect (SAS Institute, 1985). The effects of hoof health (SU vs. nSU; $1 \mathrm{df}$ ), surface (concrete vs. rubber; $1 \mathrm{df}$ ), and the interaction between hoof health and surface ( $1 \mathrm{df}$ ) were tested against an error term with $28 \mathrm{df}$.

Cows with higher gait scores (lame cows) were tested to evaluate whether they showed a greater response to the flooring treatment than cows with lower scores. The difference between the 2 surfaces (concrete minus rubber) was calculated for each variable for each cow and regressed against the average gait score of the cow on concrete and tested against an error term with 28 df (SAS Institute, 1985). Discriminant analysis was used to test how accurately each gait attribute and the overall assessment of gait (NRS) correctly classified cows with SU from those without (SAS Institute, 1985).
Last, stride overlap and tracking-up indicated the degree of front and rear hoof overlap in 2 different ways: stride overlap was measured using kinematics, and tracking-up was assessed subjectively. Because tracking-up assessed only shortness of stride (assigning a score of 0 regardless of whether the rear hoof landed on or in front of the front hoof) and stride overlap measured both underlap and overlap, the Pearson correlation coefficient with tracking-up was calculated on the underlap data only.

\section{RESULTS}

\section{Kinematic Gait Analysis}

Flooring surface affected a number of kinematic variables. Cows had longer stride lengths, higher maximum stride height, more stride overlap, spent less time in triple support during the gait cycle (3 hooves in ground contact), and walked faster on the composite rubber surface than on concrete (Table 2), yet stride duration and stance duration were not affected by flooring. Furthermore, no differences were found between cows with and without SU for any kinematic stride variables except stride height; cows with SU had lower stride heights than cows without. An interaction between hoof health and flooring surface was found for swing duration: SU cows had longer swing durations on the composite rubber surface compared with concrete, but nSU cows showed no difference between the 2 surfaces.

For several variables, cows with higher gait scores (more severe lameness) showed the greatest response to the composite rubber surface (Figure 1). The correlations between gait score (tested on concrete) and differences in kinematic variables between concrete and the composite rubber surface were greatest for stride length ( $\mathrm{r}=-0.51, P<0.01)$, swing duration $(\mathrm{r}=-0.44, P<$ 0.05 ), triple support ( $\mathrm{r}=0.59, P<0.001)$, and stride overlap $(\mathrm{r}=-0.50, P<0.01)$. However, the relationship 
A
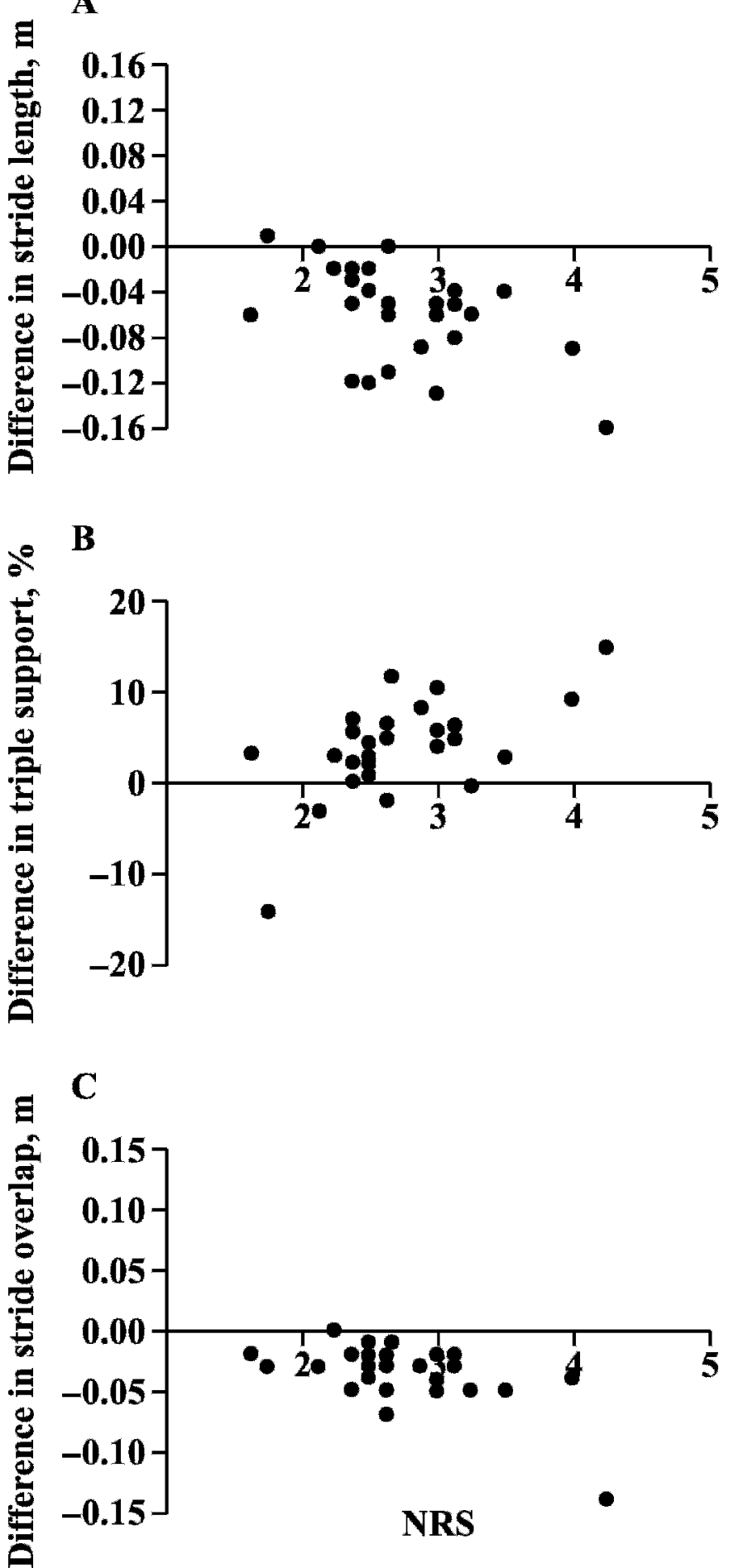

Figure 1. Mean difference between concrete and rubber (concrete minus rubber) for each cow in $\mathrm{A})$ stride length $(\mathrm{r}=-0.51, P<0.01)$, B) proportion of time in triple support $(\mathrm{r}=0.59, P<0.001)$, and $\mathrm{C})$ stride overlap $(\mathrm{r}=-0.50, P<0.01)$ plotted against the mean overall gait score (numerical rating system, NRS) for cows walking on concrete $(\mathrm{n}=30)$. between gait score and stride overlap (Figure 1C) was driven by 1 cow. Reanalysis excluding this cow showed a nonsignificant relationship $(P>0.60)$. The correlations were not significant for stride height, stride and stance duration, and speed $(P>0.35,0.98,0.53$, and 0.12 , respectively).

\section{Subjective Gait Assessment}

Intraobserver scoring consistency was high for NRS ( $\mathrm{r}=0.97, P<0.001)$, back arch $(\mathrm{r}=0.92, P<0.001)$, head bob ( $\mathrm{r}=0.84, P<0.001)$, tracking-up $(\mathrm{r}=0.96, P$ $<0.001)$, joint flexion $(\mathrm{r}=0.91, P<0.001)$, asymmetric gait $(\mathrm{r}=0.90, P<0.001)$, and reluctance to bear weight ( $\mathrm{r}=0.96, P<0.001)$. Only moderate consistency was found for abduction/adduction $(\mathrm{r}=0.68, P<0.01)$.

Overall, cow gait improved when cows walked on the composite rubber surface: NRS, tracking-up, joint flexion, asymmetric gait, reluctance to bear weight, and abduction/adduction all decreased on the rubber flooring (Table 3). Cows with SU had higher values for NRS, higher tracking-up scores, higher joint flexion scores, greater asymmetric gait scores, and more reluctance to bear weight compared with nSU cows, both on rubber and on concrete flooring. No interactions between hoof health and surface were observed for any subjective gait variables.

Cows with the highest gait scores showed the greatest improvement in NRS $(\mathrm{r}=0.46, P<0.01)$ and in reluctance to bear weight $(\mathrm{r}=0.66, P<0.001)$ when walking on the composite rubber surface compared with concrete (Figure 2). Relationships were found for trackingup $(\mathrm{r}=0.44, P<0.05)$, joint flexion $(\mathrm{r}=0.37, P<0.05)$, and asymmetric gait $(\mathrm{r}=0.40, P<0.05)$. No significant relationships were found for back arch, head bob, or abduction/adduction $(P>0.36,0.06,0.81$, respectively).

The accuracy of classifying cows into those with or without SU was high when based on NRS (71\%; 12 of 17 observations correctly classified by the model). Of all the other subjective measures, asymmetric gait correctly classified most cows (76\%; 13 of 17 observations). Back arch, tracking-up, reluctance to bear weight, head bob, and joint flexion were all less accurate at classifying cows (47 to $59 \%$ ).

As expected, the subjective and objective assessments of overlap (stride overlap and tracking-up) were negatively correlated for cows walking on concrete $(\mathrm{r}=-0.51$; $P<0.02$ ). Therefore, cows with poor tracking-up (high positive value) would also have a large underlap (high negative value).

\section{DISCUSSION}

Dairy cow gait was influenced by flooring surface. Specifically, cows had longer and higher strides, had 
Table 3. Least squares means \pm SEM of subjective gait assessment on concrete and a composite rubber surface, for cows with no sole ulcers (nSU; $n=20)$ and cows with sole ulcers (SU; $n=10$ )

\begin{tabular}{|c|c|c|c|c|c|c|c|}
\hline \multirow[b]{2}{*}{ Item $^{1}$} & \multicolumn{2}{|c|}{$\mathrm{nSU}$} & \multicolumn{2}{|c|}{$\mathrm{SU}$} & \multicolumn{3}{|c|}{$P^{2}$} \\
\hline & Concrete & Rubber & Concrete & Rubber & $\mathrm{S}$ & $\mathrm{H}$ & $\mathrm{S} \times \mathrm{H}$ \\
\hline $\begin{array}{l}\text { Numerical rating system } \\
\text { Variable }\end{array}$ & $2.5 \pm 0.1$ & $2.4 \pm 0.1$ & $3.1 \pm 0.1$ & $2.9 \pm 0.1$ & 0.010 & 0.003 & $>0.10$ \\
\hline Back arch & $9 \pm 2$ & $11 \pm 2$ & $13 \pm 2$ & $12 \pm 2$ & $>0.10$ & $>0.10$ & 0.068 \\
\hline Head bob & $4 \pm 1$ & $6 \pm 1$ & $5 \pm 1$ & $5 \pm 1$ & $>0.10$ & $>0.10$ & $>0.10$ \\
\hline Tracking up & $15 \pm 2$ & $11 \pm 2$ & $24 \pm 2$ & $19 \pm 2$ & 0.001 & 0.008 & $>0.10$ \\
\hline Joint flexion & $27 \pm 2$ & $23 \pm 2$ & $33 \pm 2$ & $29 \pm 2$ & 0.003 & 0.023 & $>0.10$ \\
\hline Asymmetric gait & $25 \pm 2$ & $23 \pm 2$ & $36 \pm 3$ & $31 \pm 3$ & 0.016 & 0.006 & $>0.10$ \\
\hline Reluctance to bear weight & $7 \pm 2$ & $6 \pm 2$ & $16 \pm 2$ & $12 \pm 2$ & 0.022 & 0.009 & $>0.10$ \\
\hline Abduction/adduction & $22 \pm 2$ & $18 \pm 2$ & $25 \pm 3$ & $23 \pm 3$ & 0.007 & $>0.10$ & $>0.10$ \\
\hline
\end{tabular}

\footnotetext{
${ }^{1}$ The numerical rating system was scored on a 5 -point scale from 1 to 5 , where $1=$ sound and $5=$ severely lame. Variables were scored on continuous 100-unit visual analog scales. Both ends of the scale had a description of the extreme forms of the condition. For example, degree of back arch had "flat" at one end (0) of the scale and "convex" at the other end (100), where "convex" represented the most extreme back arch the observer had seen in their experience.

${ }^{2} P$-values for the effects of surface (S: concrete vs. rubber), hoof health (H: nSU vs. SU), and their interaction $(\mathrm{S} \times \mathrm{H})$.
}

more overlap between front and back hooves, had longer swing durations, spent less time in triple support, and walked faster when walking on the composite rubber surface compared with walking on concrete. The overall subjective gait score (NRS) was lower and cows had greater tracking-up, improved joint flexion, a more symmetrical gait, were able to bear weight more evenly over all legs, and displayed less abduction/adduction on the composite rubber surface. These findings agree with those reported by Telezhenko and Bergsten (2005).

The faster walking speed, greater stride overlap, reduced time in triple support, and less reluctance to bear weight suggest that cows had better footing on the softer, high-friction composite rubber surface than on concrete. Because hooves were able to sink into the rubber flooring, more contact was created between hooves and the flooring surface. The composite rubber surface had a higher frictional coefficient than concrete (Rushen and de Passillé, 2006), which likely added to a more secure footing. Indeed, the authors reported a lower incidence of slipping when cows were walking on similar flooring. The results in the current study support earlier work showing that cows adjusted their manner of walking in response to surface softness and friction: Phillips and Morris (2001) reported that cows had longer strides and more joint angulation on highvs. low-friction concrete.

The composite rubber surface also provided more cushioning than concrete, and this cushioning improved cow mobility (Rushen and de Passillé, 2006). Unfortunately, there has been no detailed work in this area for cattle or other quadrupeds, although some work has been reported in the human literature. For example, one study reported that providing more cushioning (i.e., wearing athletic shoes compared with walking barefoot) reduced the peak forces experienced at impact and reduced the rate of loading when walking on concrete (Lafortune and Hennig, 1992). In the current study, the composite rubber surface also likely reduced the rate of limb loading. Future work needs to examine quantitative assessments of weight bearing during walking, especially in relation to surfaces with differing compressibility.

Some gait measures were not affected by the softer, higher-friction composite rubber surface (stride duration, stance duration, back arch, and head bob). Indeed, some of these gait features may be unresponsive to treatment differences. For example, recent work indicated that differences in cow gait before and after milking were unable to be detected by swing duration, back arch, and head bob (Flower et al., 2006).

Gait measures, in general, had weaker relationships with hoof health in the current study compared with the findings reported in Flower et al. (2005) and Flower and Weary (2006). Because the gait measures in all 3 studies were recorded and analyzed in the same way, differences in housing and in the assessment of hoof health may explain these relationships. First, the standing and walking surfaces for cows in Flower et al. (2005) were more abrasive (cows were loose-housed in concrete pens with deep-bedded sand stalls vs. cows housed in tie-stalls on rubber mattresses) and probably resulted in a faster rate of hoof wear than in the current study, reducing the time required for hemorrhages to become visible on the surface of the sole. This difference may have meant that the delay between gait and hoof scoring suitable in the first study was no longer suitable in the current study, reducing our ability to detect dif- 
A
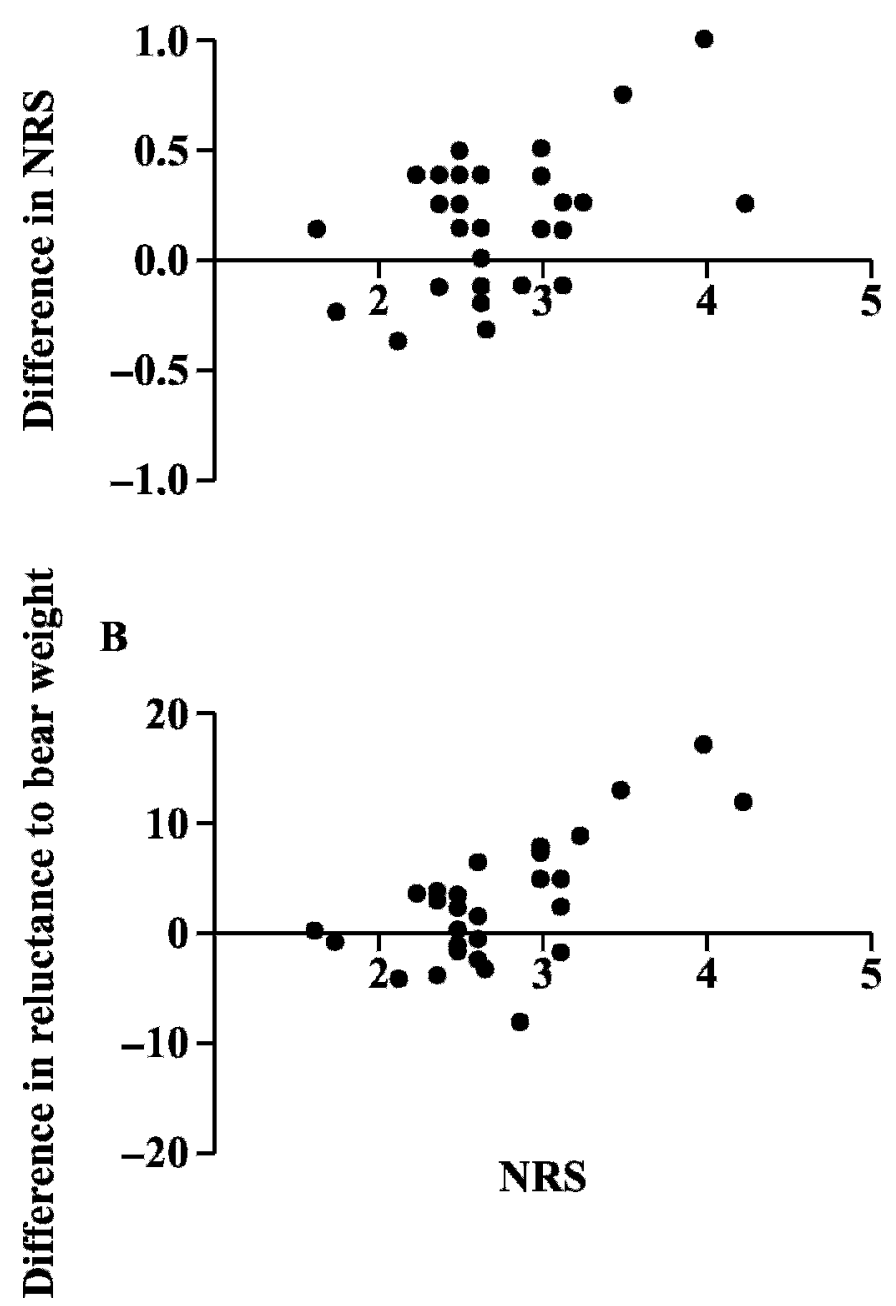

Figure 2. Mean difference between concrete and rubber (concrete minus rubber) for each cow in A) overall gait score (numerical rating system, NRS; $r=0.46, P<0.01$ ) and B) reluctance to bear weight $(\mathrm{r}=0.66, P<0.001)$ plotted against the mean overall gait score (NRS) for cows walking on concrete $(\mathrm{n}=30)$.

ferences in gait associated with SU. Second, although the same observer analyzed gait in both studies, hoof examinations were conducted by different observers, using different lesion scoring systems.

This study compared an objective measure of overlap (stride overlap) with a subjective measure (trackingup). To our knowledge, this is the first study to compare the 2 approaches directly. Although these variables were related, variation in stride overlap accounted for only $26 \%$ of the variance in the subjectively assessed tracking-up. This lack of fit may have been because the 2 variables recorded different aspects of overlap: Stride overlap was based on an average of the left and right sides, whereas tracking-up assessed both the left and right sides, but assigned a score based on the worst side. Although both measures were equally effective at distinguishing the effect of flooring surface, the subjective measure was more successful at identifying cows with SU. This last result suggests that the subjective measure captured some (as yet unidentified) aspect of gait impairment not included in the kinematic measure of stride overlap.

Gait measures for cows walking on concrete were similar to those in previous work (Flower et al., 2005; Flower and Weary, 2006), although some measures, such as stride length, NRS, and back arch were lower in the current study, perhaps because of differences between herds and housing systems. The gait measures demonstrated that relying on a single behavioral attribute to identify cows with SU, as in Sprecher et al. (1997), could be misleading because several cows in the current study would have been misclassified using just back arch. Indeed, the discriminant analysis was unable to form a combination of gait measures that was any more successful at assigning cows to hoof health groups than the NRS.

An important finding of this study was that for a number of gait variables (both kinematic and subjective), the subjective gait score affected how the cow responded to the flooring surface. The degree to which the composite rubber surface reduced time in triple support; increased stride overlap, stride length, and swing duration; and reduced overall gait score and reluctance to bear weight was most obvious with cows with high gait scores. These results suggest that the lamest cows benefited the most from a softer, higherfriction surface. Further work is needed to investigate which properties of the composite rubber flooring are most important for cow gait. Some work on surface friction (Phillips and Morris, 2001) and softness (Rushen and de Passillé, 2006) has been reported, but the effects of other flooring properties, such as abrasiveness, on lame cows have not been investigated.

In conclusion, most measures demonstrated a clear improvement in gait when cows walked on the composite rubber surface vs. concrete flooring. This suggests that rubber flooring provided more secure footing and was more comfortable for cows to walk on. The lamest animals had the greatest improvement, suggesting that these cows may especially benefit from more comfortable flooring.

\section{ACKNOWLEDGMENTS}

We thank the staff and students at the Dairy and Swine Research and Development Centre, especially Marie-Josée Sirois, Isabelle Blanchet, Christian Croisetière, Jerry Dumont, Huibert Oóstra, and Naomi Both- 
eras, for their help. The research was funded by the Dairy Farmers of Canada and MII funds of Agriculture and Agri-Food Canada. Further support was obtained from the Natural Sciences and Engineering Research Council of Canada through the Industrial Research Chair in Animal Welfare, and by contributions from the British Columbia (BC) Society for the Prevention of Cruelty to Animals, the BC Veterinary Medical Association, the Beef Cattle Industry Development Fund, the BC Dairy Foundation, and many others listed at http://www.landfood.ubc.ca/animalwelfare/.

\section{REFERENCES}

Bergsten, C., and B. Frank. 1996. Sole haemorrhages in tied primiparous cows as an indicator of periparturient laminitis: Effects of diet, flooring and season. Acta Vet. Scand. 37:383-394.

Clarkson, M. J., D. Y. Downham, W. B. Faull, J. W. Hughes, F. J. Manson, J. B. Merritt, R. D. Murray, W. B. Russell, J. E. Sutherst, and W. R. Ward. 1996. Incidence and prevalence of lameness in dairy cattle. Vet. Rec. 138:563-567.

Cook, N. B. 2003. Prevalence of lameness among dairy cattle in Wisconsin as a function of housing type and stall surface. J. Am. Vet. Med. Assoc. 223:1324-1328.

Flower, F. C., D. J. Sanderson, and D. M. Weary. 2006. Effects of milking on dairy cow gait. J. Dairy Sci. 89:2084-2089.

Flower, F. C., D. J. Sanderson, and D. M. Weary. 2005. Hoof pathologies influence kinematic measures of dairy cow gait. J. Dairy Sci. 88:3166-3173.

Flower, F. C., and D. M. Weary. 2006. Hoof pathologies influence subjective assessments of dairy cow gait. J. Dairy Sci. 89:139-146.

Green, L. E., V. J. Hedges, Y. H. Schukken, R. W. Blowey, and A. J. Packington. 2002. The impact of clinical lameness on the milk yield of dairy cows. J. Dairy Sci. 85:2250-2256.

Hernandez, J. A., E. J. Garbarino, J. K. Shearer, C. A. Risco, and W. W. Thatcher. 2005. Comparison of the calving-to-conception interval in dairy cows with different degrees of lameness during the prebreeding postpartum period. J. Am. Vet. Med. Assoc. 227:1284-1291.
Lafortune, M. A., and E. M. Hennig. 1992. Cushioning properties of footwear during walking: Accelerometer and force platform measurements. Clin. Biomech. 7:181-184.

Lischer, C. J., and P. Ossent. 2000. Sole ulcers in dairy cattle-What's new about an old disease? Pages 46-48 in Proc. XI Int. Symp. Disorders Rumin. Digit, Parma, Italy.

Manson, F. J., and J. D. Leaver. 1988. The influence of concentrate amount on locomotion and clinical lameness in dairy cattle. Anim. Prod. 47:185-190.

Neveux, S., D. M. Weary, J. Rushen, M. A. G. von Keyserlingk, and A. M. de Passillé. 2006. Hoof discomfort changes how dairy cattle distribute their body weight. J. Dairy Sci. 89:2503-2509.

NRC. 2001. Nutrient Requirements of Dairy Cattle. 7th rev. ed. National Academy Press, Washington, DC.

O'Callaghan, K. 2002. Lameness and associated pain in cattle-Challenging traditional perspectives. In Pract. 24:214-219.

Phillips, C. J. C., and I. D. Morris. 2001. The locomotion of dairy cows on floor surfaces with different frictional properties. J. Dairy Sci. 84:623-628.

Rushen, J., and A. M. de Passillé. 2006. Effects of roughness and compressibility of flooring on cows' locomotion. J. Dairy Sci. 89:2965-2972.

SAS Institute. 1985. SAS User's Guide: Statistics. Version 5 ed. SAS Inst., Inc., Cary, NC.

Somers, J. G. C. J., K. Frankena, E. N. Noordhuizen-Stassen, and J. H. M. Metz. 2005. Risk factors for interdigital dermatitis and heel erosion in dairy cows kept in cubicle housing in The Netherlands. Prev. Vet. Med. 71:23-34.

Sprecher, D. J., D. E. Hostetler, and J. B. Kaneene. 1997. A lameness scoring system that uses posture and gait to predict dairy cattle reproductive performance. Theriogenology 47:1179-1187.

Telezhenko, E., and C. Bergsten. 2005. Influence of floor type on the locomotion of dairy cows. Appl. Anim. Behav. Sci. 93:183-197.

Vokey, F. J., C. L. Guard, H. N. Erb, and D. M. Galton. 2001. Effects of alley and stall surfaces on indices of claw and leg health in dairy cattle housed in a free-stall barn. J. Dairy Sci. 84:2686-2699.

Wells, S. J., L. P. Garber, and B. A. Wagner. 1999. Papillomatous digital dermatitis and associated risk factors in US dairy herds. Prev. Vet. Med. 38:11-24.

Whay, H. R., A. E. Waterman, and A. J. F. Webster. 1997. Associations between locomotion, claw lesions and nociceptive threshold in dairy heifers during the peri-partum period. Vet. J. 154:155-161.

Whitaker, D. A., A. I. Macrae, and E. Burrough. 2004. Disposal and disease rates in British dairy herds between April 1998 and March 2002. Vet. Rec. 155:43-47. 